V. 12 N. 2

MAI-AGO 2016

ISSN 2317-6172

\section{Direito e teorias ideal e não ideal da justiça}

LAW, IDEAL THEORY AND NON-IDEAL THEORY OF JUSTICE

\title{
Resumo
}

0 artigo discute a importância de teorias ideais e não ideais da justiça para avaliar propostas de mudança pontual da legislação. Concordando, a esse respeito, com Sen $(2006$; 2009), defendo que teorias ideais (no sentido de teorias de "estado final") não são nem necessárias nem suficientes para comparações entre sociedades imperfeitas. Isso, contudo, não significa que teorias ideais não possam ser úteis para essas comparações e, em consequência, para a avaliação de propostas de alteração do status quo. No entanto, à medida que uma teoria ideal se mostre um ponto de partida digno de consideração para as comparações relativas a alterações legislativas em circunstâncias não ideais, é preferível que a teoria em questão seja uma teoria total, isto é, que abranja a totalidade do objeto da justiça (no caso de teorias institucionalistas, como a de Rawls, a totalidade da estrutura básica da sociedadel em vez de se restringir a uma área do direito em particular.

Recebido: 17.07.2014 Aprovado: 27.04.2016

DOI: http://dx.doi.org/10.1590/2317-6172201615

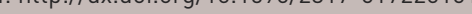

1 Universidade Federal de Minas Gerais Belo Horizonte - MG - Brasil

\section{Palavras-chave}

Justiça; alterações legislativas; teoria ideal; teoria não ideal; Sen.

\begin{abstract}
The article discusses the importance of ideal and non-ideal theories of justice for the assessment of proposals of legal reform. Agreeing, on this respect, with Sen (2006; 2009), I argue that ideal theory (in the sense of "end-state" theory) is neither necessary nor sufficient for comparisons between imperfect societies. This, however, does not mean that ideal theory may not be useful to those comparisons and, by extension, to the analysis of proposals of change. But to the extent that an ideal theory proves to be a point of departure worth considering on evaluating proposals of law amendment, it is preferable that such theory encompasses the entire scope of justice (in the case of institutionalist theories like Rawls's, this means the basic structure of society as a wholel instead of being circumscribed to just one of the several legal areas.
\end{abstract}

\section{Keywords}

Justice; legal change; ideal theory; non-ideal theory; Sen.

\section{(cc) BY-NC}




\section{INTRODUÇÃO}

É natural que propostas de reforma legislativa pontual sejam defendidas ou atacadas em termos de justiça. Mesmo admitindo que a justiça não seja a única consideração relevante, soa como truísmo dizer que, todo o restante sendo igual, deveríamos preferir que uma certa área do direito, como o direito privado, seja mais e não menos justa. Uma característica de boa parte da teorização contemporânea quanto à justiça social, no entanto, consiste em inquirir sobre a justiça em circunstâncias diferentes das sociedades em que vivemos. Rawls (1999a), para ficar com o exemplo mais proeminente, trata como desiderato primordial da sua teoria da justiça determinar os princípios a serem seguidos pelas instituições (ou "estrutura básica") de uma sociedade perfeitamente justa. É duvidoso se os preceitos de uma teoria da justiça como tal entendida são aproveitáveis para apreciar propostas de reforma da legislação de sociedades reais cujas instituições divergem, de um modo geral, das de uma sociedade perfeitamente justa. Em vez de uma teoria concebida para circunstâncias ideais, mudanças no direito de sociedades reais talvez devam ser apreciadas à luz de critérios menos ambiciosos de justiça que se restrinjam à área da legislação em questão e, ao fazê-lo, deixem de lado a presunção de conformidade das demais instituições com os ditames da justiça.

Neste artigo, defendo, em síntese, as seguintes afirmações. Primeiro, uma teoria ideal de justiça (entendida como teoria de "estado final", isto é, como teoria sobre um estado de coisas perfeitamente justo) não é nem necessária nem suficiente para comparações que sirvam como base para avaliar propostas de reforma da legislação em circunstâncias não ideais. Essa opinião, que coincide com o que Sen $(2006$; 2009) alega acerca de teorias transcendentais da justiça, é defendida contra algumas críticas que os trabalhos do mesmo Sen têm suscitado. Segundo, e não obstante o fato de não ser nem necessária nem suficiente, uma teoria ideal é potencialmente útil para as comparações feitas sob condições de imperfeita justiça, porque os princípios de justiça característicos de sociedades ideais podem ajudar a determinar os princípios de justiça válidos para sociedades reais. Terceiro, à medida que a afinidade entre os princípios válidos para circunstâncias ideais e não ideais seja grande o suficiente para permitir que os primeiros sirvam de base à descoberta dos segundos, é preferível que a teoria ideal considerada para as comparações entre estados de coisas imperfeitos seja uma teoria total, isto é, compreensiva de todo o objeto da justiça. Admitindo-se que esse objeto corresponda à totalidade das instituições de uma sociedade, a teoria ideal que se deve ter em vista quando se trata de avaliar propostas de alteração é uma teoria relativa à totalidade das instituições, e não restrita à área do direito.

O artigo é organizado como segue. Na primeira seção, apresento três maneiras de distinguir teoria ideal e teoria não ideal sobre a justiça. Na segunda, diferencio as noções de teoria total e parcial e chamo a atenção para um inconveniente das teorias desse segundo gênero. A terceira seção apresenta e rebate críticas ao ponto de vista de que teorias ideais (entendidas como teorias de estado final) não são nem necessárias nem suficientes para comparações nas 
circunstâncias não ideais. Na quarta seção, afirmo que, apesar de nem necessária nem suficiente, uma teoria ideal pode ser útil para comparações destinadas a avaliar propostas de mudança da legislação, mas que, em tal caso, é preferível que a teoria em questão seja uma teoria compreensiva de todo o objeto da justiça, em vez de limitada a uma área do direito em particular.

\section{JUSTIÇA: TEORIAS IDEAIS E NÃO IDEAIS}

Em uma recente revisão da literatura, Valentini (2012) refere três maneiras de distinguir teoria ideal e teoria não ideal. De acordo com uma delas, uma teoria ideal é uma teoria de “estado final” porque descreve um estado de coisas perfeitamente justo, isto é, em relação ao qual não há melhora possível. Teorias não ideais, em contraposição, seriam teorias transicionais, cujo objeto são as medidas a tomar em circunstâncias não perfeitamente justas com o fim de alcançar a perfeita justiça.

Considero esse modo de distinguir teoria ideal e teoria não ideal útil, mas falho por dar a entender que toda teoria não ideal deva ter como referência uma teoria ideal, já que o interesse da primeira não seria outro senão o de determinar como chegar, a partir de circunstâncias imperfeitas, ao estado de coisas descrito pela segunda. Em contrapartida, é possível considerar teorias não ideais como meramente comparativas de estados de coisas sob o ponto de vista da justiça (SEN, 2009). Como teoria comparativa, uma teoria não ideal permite tão somente avaliar se a tomada de certa medida leva ou não a um estado de coisas superior ao atual em termos de justiça. ${ }^{1}$

Vejamos agora os outros dois modos de distinguir teoria ideal e teoria não ideal a que Valentini (2012) alude. A diferença entre uma teoria ideal e uma teoria não ideal também pode dizer respeito às presunções fáticas (ora referidas como "idealizações”, ora como “abstrações”) características de cada teoria, como, por exemplo, presunções sobre a abundância de recursos naturais ou sobre a capacidade dos seres humanos para o altruísmo. ${ }^{2}$ Assim entendida

1 Afirmar que o contraste entre teoria ideal e teoria não ideal é um contraste entre teoria do estado final e teoria comparativa não significa que a primeira não possa envolver comparações. Uma das maneiras de defender um estado de coisas como perfeitamente justo é mediante a comparação com estados de coisas diversos. Rawls (1999a), por exemplo, vale-se eminentemente da comparação com outros princípios, em particular o da máxima utilidade média, para defender os princípios da justiça como equidade. Crucial para a distinção é que, seja ou não mediante comparação, uma teoria ideal (no sentido de teoria de estado final) acaba descrevendo um estado de coisas perfeitamente justo (isto é, insuscetível de melhora em termos de justiça), enquanto que uma teoria não ideal (como teoria comparativa) limita-se a servir de base para comparações.

2 Também é apresentada como distinção entre teorias mais e menos "sensíveis a fatos" (fact-sensitive). Ver Hamlin e Stemplowska (2012, p. 51). 
a contraposição, não haveria uma diferença categórica entre teorias ideais e teorias não ideais (VALENTINI, 2012, p. 660; HAMLIN; STEMPLOWSKA, 2012, p. 51), mas sim um contínuo em que teorias se classificam como mais ou menos ideais de acordo com a plausibilidade das suas presunções, tratando-se como mais ideais as teorias cujas presunções são menos plausíveis. ${ }^{3}$

Não é objetivo deste artigo inquirir sobre o quão plausíveis devem ser as presunções fáticas de quem teoriza sobre a justiça (em outras palavras, sobre o quão ideal ou não ideal, no sentido por último mencionado, uma teoria deve ser). Para os meus propósitos, é suficiente observar que teorias de estado final podem ocupar qualquer ponto do contínuo recém-referido. Ao descrever um estado de coisas perfeitamente justo, uma teoria de estado final pode fazer presunções um tanto fantasiosas sobre, por exemplo, a capacidade dos seres humanos para atuar de modo justo ou, ao contrário, renunciar a quaisquer hipóteses de mudança comportamental que considere pouco plausíveis. Em resumo, tanto teorias próximas do extremo ideal quanto do não ideal (no que se refere à plausibilidade das presunções) podem ser uma teoria ideal no sentido de uma teoria de estado final.

Uma terceira maneira de fazer a distinção entre teoria ideal e teoria não ideal é, por fim, a que diz respeito à conformidade ou obediência (compliance). A diferença entre teoria ideal e teoria não ideal residiria, em tal caso, no fato de as primeiras presumirem plena conformidade com os ditames da justiça, presunção essa que não se verificaria nas segundas. ${ }^{4}$

A distinção baseada no critério da conformidade pode se mostrar subsumível à distinção anterior, entre teorias baseadas em presunções fáticas mais e menos plausíveis. Afinal, a presunção de que todos se comportam de maneira conforme aos ditames da justiça não é nada além do que a presunção sobre um fato. Além disso, para critérios de justiça com certo grau de exigência, essa é uma presunção cuja plausibilidade leva uma teoria a se aproximar do extremo ideal no sentido da distinção feita acima.

Há, todavia, um problema com o critério da conformidade que justifica examiná-lo a parte. Tal como recém-formulado, esse critério é indeterminado em relação àqueles ou àquilo cuja conformidade está em questão. Trata-se de conformidade por parte dos cidadãos em geral ou apenas das instituições ou, para usar a expressão de Rawls, da estrutura básica da sociedade? No primeiro caso, o critério em questão levaria a classificar como teoria ideal uma teoria que presumisse a obediência de todos os cidadãos aos preceitos da justiça (ou ao menos da maior parte deles a maior parte do tempo). No segundo, o que importa não

3 Uma maneira similar de classificação é a que tem em vista não a plausibilidade, mas o otimismo das presunções, tratando uma teoria como tão mais ideal quanto mais otimistas forem as suas presunções.

4 Além de Valentini (2012, p. 655-656), a distinção baseada no critério da conformidade é mencionada em Hamlin e Stemplowska (2012, p. 49-50). 
é o comportamento dos cidadãos, mas tão somente a conformidade das instituições que compõem a estrutura básica da sociedade com a justiça.

Considere agora duas hipóteses, uma na qual toda teoria de estado final será necessariamente uma teoria ideal no sentido do critério da conformidade, e outra na qual a pertinência desse critério é duvidosa. Primeiro, a hipótese na qual toda teoria de estado final é, de acordo com o critério da conformidade, uma teoria ideal: suponha que uma teoria da justiça tenha como exclusivo objeto a estrutura básica da sociedade, e que se entenda conformidade como conformidade da estrutura básica da sociedade à justiça. Na versão de estado final, o que uma teoria da justiça com objeto limitado à estrutura básica da sociedade faz não é mais do que descrever as instituições de uma sociedade perfeitamente justa. Nada mais afora essas instituições, nem mesmo o comportamento dos cidadãos em geral, importa para uma teoria como essa. ${ }^{5}$ Como se trata, além disso, de uma teoria de estado final, o que essa teoria descreve, por definição, são as instituições de uma sociedade perfeitamente justa e, como tais, instituições que se conformam aos preceitos da justiça. Mais do que mera presunção fática, plena conformidade da estrutura básica da sociedade à justiça em um caso como esse é, portanto, uma característica definicional.

Passemos agora à segunda hipótese, em que a pertinência do critério da conformidade é duvidosa: suponha novamente uma teoria da justiça restrita à estrutura básica da sociedade, e que o critério da conformidade desta vez se refira aos cidadãos em geral, e não à estrutura básica da sociedade. Em um caso como esse, o critério da conformidade classificaria como teoria ideal uma teoria de estado final que presumisse a obediência dos cidadãos aos preceitos da justiça, e como teoria não ideal uma teoria análoga na qual se abrisse mão da referida presunção. O problema com essa distinção é: se uma teoria de estado final se ocupa exclusivamente com a estrutura básica da sociedade, e então declara como perfeitamente justa uma sociedade cuja estrutura básica da sociedade atende a certos princípios, que importância pode ter para essa teoria como os cidadãos se comportam em seu dia a dia? Por um lado, não há dúvida de que duas sociedades serão bem diferentes se, apesar de possuírem ambas uma estrutura básica da sociedade conforme à justiça, em uma delas houver contumaz obediência à lei e na outra não. Essa será, no entanto, uma diferença irrelevante para a justiça se, como estipulado, nos dois casos as instituições forem perfeitamente justas e a justiça tiver a estrutura básica da sociedade como seu objeto exclusivo. Por que, então,

5 O comportamento dos cidadãos para uma teoria como a cogitada acima pode interessar indiretamente caso seja importante para avaliar a conformidade da estrutura básica da sociedade à justiça (voltarei a esse ponto). No caso de Rawls (1999a, p. 398), por exemplo, faz parte da definição de uma estrutura básica da sociedade justa que ela seja estável. Logo, a obediência dos cidadãos (ao menos da maior parte pela maior parte do tempo) importa porque, se uma ordem institucional for incapaz de induzir tal obediência, não será estável nem, em consequência, justa. 
classificar uma teoria como teoria ideal ou teoria não ideal em razão de algo (o comportamento dos cidadãos) irrelevante para a justiça?

Poder-se-ia ponderar que a obediência às leis pelos cidadãos importa, sim, para uma teoria de estado final restrita à estrutura básica da sociedade porque as instituições de uma sociedade não serão estáveis se as leis não forem em geral obedecidas, e nenhuma estrutura básica da sociedade poderá ser considerada perfeitamente justa se não for estável. Isso pode ser correto, mas não desmente a afirmação segundo a qual se a justiça tem como único objeto a estrutura básica da sociedade, então, depois que as instituições de uma sociedade perfeitamente justa forem definidas, o comportamento dos cidadãos deixará de ter qualquer relevância para a justiça. Além disso, se o comportamento dos cidadãos for importante para determinar que instituições são perfeitamente justas (tal como, por exemplo, se só for o caso de considerar a estrutura básica da sociedade perfeitamente justa se ela se mostrar capaz de incitar obediência), então a diferença entre uma teoria que leva a sério o problema da obediência dos cidadãos às leis e outra que simplesmente presume essa obediência é mais do que uma mera diferença entre teoria ideal e teoria não ideal. É uma diferença entre uma teoria que enfrenta um problema que, do ponto de vista da justiça, não pode ser ignorado e outra que trata esse mesmo problema como se não existisse, mostrando-se falha por essa razão.

\section{JUSTiÇA E ÁreAs do Direito}

Qual teoria da justiça, ideal ou não ideal, importa para uma área do direito em particular, tal como o direito privado? Considere, para começar, o caso de uma teoria de estado final cujo objeto seja exclusivamente a estrutura básica da sociedade. Admitindo-se que o direito privado seja parte da estrutura básica da sociedade, ${ }^{6}$ uma teoria cujo propósito seja descrever a estrutura básica da sociedade de uma sociedade perfeitamente justa é potencialmente relevante para o direito privado. Digo "potencialmente" (em vez de "necessariamente”) porque a teoria em questão talvez não faça qualquer recomendação em particular ou sequer requeira a existência do que costumamos designar como direito privado. Ainda que essa última hipótese seja pouco provável, vale salientar que a estrutura básica da sociedade talvez consiga satisfazer aos princípios de uma teoria como a cogitada com diferentes regimes de direito privado. Além disso, tal como observado na seção anterior, uma teoria de estado final (a exemplo de qualquer outra do gênero) limitada à estrutura básica da sociedade pode ser classificada como mais ou menos ideal no que se refere à plausibilidade das suas presunções fáticas.

6 Essa afirmação não é incontroversa. Ripstein (2004) defende uma interpretação da estrutura básica da sociedade de Rawls que não inclui o direito privado. Penso, no entanto, que os argumentos de Ripstein são corretamente refutados por Kordana e Tabachnick (2006). 
Considere, a seguir, o caso do que Robeyns (2008) designa como “justiça parcial”. Aplicada ao direito privado, essa noção corresponde a uma teoria que se restrinja a essa área do direito, sem inquirir, portanto, sobre o que a justiça demanda como um todo. ${ }^{\mathbf{7}}$ Como classificar uma teoria assim? Note que a expressão "justiça parcial” sugere que o inteiro âmbito da justiça é maior do que o atualmente considerado. Em outras palavras, dizer que uma teoria da justiça do direito privado é um exemplo de teoria parcial leva a depreender que o direito privado é parte, mas não a totalidade, do objeto da justiça. Para ficar com o exemplo mais usado até aqui, a justiça do direito privado é uma justiça parcial, no sentido recémreferido, se o objeto da justiça for a estrutura básica da sociedade (admitindo-se que o direito privado corresponda a parte, mas não à totalidade, dessa estrutura). Vale ressaltar que a questão de saber qual é o objeto da justiça é deixada aberta aqui. Talvez a justiça não tenha nada a ver com o direito privado, ou tenha a ver com o direito privado e com mais nenhuma área da legislação. Quando se diz, contudo, que a justiça do direito privado é uma justiça parcial, o que se insinua é que o direito privado constitui parte (parte, apenas) do objeto da justiça.

Retorno à questão sobre o modo de classificar uma teoria da justiça restrita (como teoria parcial) a uma determinada área do direito. Uma teoria da justiça do direito privado é de estado final se, em conformidade com os termos da classificação apresentada na seção anterior, tiver como propósito descrever essa área da legislação em uma sociedade perfeitamente justa. Como teoria parcial, ela se distingue por deixar de lado o que, embora pertença ao objeto da justiça, está fora do âmbito do direito privado (para a discussão que segue, presumirei que o objeto da justiça seja a estrutura básica da sociedade).

Pois bem, uma questão a examinar é se há justificativa metodológica para uma teoria nos moldes recém-citados. Se o objeto da justiça é a estrutura básica da sociedade, a questão importante para uma teoria de estado final não será a de saber como é a estrutura básica da sociedade (e não apenas uma de suas partes, como o direito privado) de uma sociedade perfeitamente justa? Pode-se tentar defender o projeto de uma teoria de estado finado direito privado com o argumento de que a enormidade da tarefa de descrever uma estrutura básica da sociedade perfeitamente justa requeira divisão do trabalho, e que a descrição de um direito privado perfeitamente justo é útil filosoficamente como meio de responder à questão mais abrangente relativa a uma estrutura básica da sociedade perfeitamente justa. É impossível saber de antemão, todavia, o quanto uma estrutura básica da sociedade perfeitamente justa pode ser definida a partir de respostas a problemas parciais de justiça (como os da justiça do direito privado, justiça da tributação, justiça da saúde etc.) e o quanto, ao

7 Os exemplos que a própria Robeyns (2008, p. 344) dá de justiça parcial são os de justiça limitada à saúde, à família e ao gênero. 
contrário, a ideia de uma estrutura básica da sociedade perfeitamente justa se opõe a essas respostas parciais por não permitir que a justiça de uma parte da estrutura básica da sociedade seja determinada de maneira independente das demais (SIMMONS, 2010, p. 22). ${ }^{\mathbf{8}}$

Convém observar, por fim, que uma teoria da justiça circunscrita a uma área do direito também pode se limitar a servir de base para a comparação de diferentes normas ou regimes, sem enfrentar a questão de saber se algum desses é condição necessária para uma sociedade perfeitamente justa. Uma teoria nesses moldes é, pois, comparativa, e não de estado final.

Nesta seção, defendi, em suma, o seguinte: se o objeto da justiça é a estrutura básica da sociedade (e o direito uma parte dessa estrutura), então uma teoria de estado final que envolva certa área do direito como o direito privado ou é uma teoria total, isto é, que descreve a totalidade de uma estrutura básica da sociedade perfeitamente justa, ou é uma teoria parcial limitada a essa área. Como teoria parcial, entretanto, uma teoria de estado final se torna incapaz de oferecer uma descrição acurada da área da legislação em questão em uma sociedade perfeitamente justa à medida que essa descrição dependa da conformação das demais partes da estrutura básica da sociedade e, portanto, de algo que extrapola os limites da teoria. Uma teoria sobre uma área do direito pode, em contrapartida, ser comparativa, caso desconsidere o problema de uma sociedade perfeitamente justa (e do papel da área em apreço em uma sociedade como essa) e se limite a permitir a comparação entre diferentes normas ou regimes.

Se o ideal (por exemplo) de um direito privado perfeitamente justo e, mais ainda, de uma estrutura básica da sociedade (na qual se inclua o direito privado) perfeitamente justa for difícil de alcançar, a vantagem de uma teoria comparativa consiste em permitir que se avaliem propostas de reforma do direito privado em circunstâncias não ideais. Outra possível vantagem é que uma teoria comparativa dispensa inquirir sobre como seriam as instituições de uma sociedade perfeitamente justa.

8 A dificuldade a que o texto alude não é meramente a de que os princípios de um setor da estrutura básica da sociedade podem ter a sua aplicação restringida a fim de evitar a contradição com princípios de outros setores, uma dificuldade à qual Robeyns (2008, p. 349) alude com o exemplo da justiça (parcial) de gênero, cujos princípios podem ter a sua aplicação limitada em razão da tensão com o que a justiça venha a requerer em relação a crianças. Isso é verdade, mas não é tudo. Princípios de justiça parcial podem não ser suscetíveis sequer de uma definição prima facie sem levar em conta o modo como atualmente se conformam as demais partes da estrutura básica da sociedade. Esse pode ou não ser o caso de instituições como as do direito privado, mas, se for, o projeto da justiça parcial é posto em xeque de maneira mais séria, porque se torna um projeto destituído de sentido em vez de apenas caracterizado pela provisoriedade dos seus resultados, ou, ao menos, tão destituído de sentido quanto mais mutuamente dependentes forem as diferentes partes da estrutura básica da sociedade no que toca a atender aos requerimentos de uma sociedade perfeitamente justa. 
Na próxima seção, entretanto, examino argumentos segundo os quais essa vantagem é ilusória. De acordo com esses argumentos, uma teoria comparativa até pode permitir avaliar propostas de reforma em circunstâncias não ideais, mas isso não torna dispensável uma teoria de estado final, porque tal teoria é uma condição necessária para comparações em circunstâncias não ideais. As implicações dessa afirmação seriam ainda mais impressionantes caso seja acertada a hipótese de que o projeto de uma teoria de estado final parcial confinada a uma área do direito não é viável em razão da relação de dependência entre a área em questão e as demais partes de uma estrutura básica da sociedade perfeitamente justa. Junto com a proposição de que uma teoria de estado final é condição necessária para qualquer comparação, a hipótese em questão, caso confirmada, levaria à conclusão de que não é possível comparar validamente diferentes normas em circunstâncias não ideais sem uma teoria sobre uma estrutura básica da sociedade perfeitamente justa.

\section{Teorias de estado final e comparações: Sen e Seus críticos}

Sen $(2006 ; 2009)$ argumenta que teorias de estado final (que ele designa como teorias transcendentais) não são nem necessárias nem suficientes para comparações sobre a justiça de diferentes estados de coisas em sociedades imperfeitas. Nesta seção, apresento e examino os argumentos de Sen, bem como algumas críticas que lhes têm sido feitas.

Começo com o ponto relativo à suficiência, o menos controvertido. Sen afirma que uma teoria de estado final não é suficiente para a realização de comparações em circunstâncias não ideais. Por que não? Pode-se cogitar que, ao descrever um estado de coisas perfeitamente justo, uma teoria proveja a base para comparações entre estados imperfeitos, os quais podem ser ordenados de acordo com a maior ou menor proximidade com um estado perfeitamente justo. Uma vez aceito esse critério de proximidade, uma teoria de estado final seria suficiente para a realização de comparações.

O critério da proximidade padece, todavia, de dois problemas: tem de possuir alguma precisão, sob pena de não se prestar a comparação alguma e (uma vez interpretado de modo a alcançar mínima precisão) tem de ser defendido. Primeiro, sobre o problema da precisão: Sen $(2009$, p. 16) pondera corretamente que dois estados de coisas podem ser imperfeitos porque se diferenciam do estado final em diferentes dimensões; por exemplo, em um deles a riqueza está mal distribuída, enquanto no outro uma minoria étnica é vítima de discriminação. Em tais casos, dizer qual dos dois objetos da comparação está mais próximo do ideal com base em um critério de proximidade requer alguma definição sobre como tratar "distâncias" qualitativamente diferentes."

9 Convém notar que uma regra de prioridade válida para circunstâncias ideais não necessariamente implica um julgamento sobre a proximidade de estados não ideais. Veja o caso de uma teoria de estado 
Outra razão, esta não mencionada por Sen, para que o critério da proximidade tenha de ser precisado é a que se refere à "dependência da trajetória” (path dependence). A distância em relação ao ideal deve ser avaliada com base apenas nas características de um estado de coisas imediatamente alcançável, ou também de acordo com outros estados de coisas cuja probabilidade é uma função do primeiro ${ }^{10}$ Para exemplificar, imagine que um estado A esteja mais próximo do ideal do que um estado B. B, no entanto, aumenta a probabilidade subsequente de um estado de coisas $\mathrm{C}$, que está ainda mais próximo do ideal do que A. Ao comparar A e B segundo o critério da proximidade, devo considerar a propensão de B a dar lugar a C? Se sim, que peso devo atribuir a essa característica de B?

O segundo problema é o da defensabilidade. Será que a pergunta correta a fazer quando se trata de eleger entre dois estados de coisas não ideais é o quão próximos eles se encontram do estado ideal? Isso soa tão mais duvidoso quanto mais discrepantes do ideal os estados a comparar se mostrem e quanto mais difícil for a realização do ideal em questão. Se estamos tratando de duas sociedades grosseiramente imperfeitas, será mesmo que a estratégia correta para determinar qual dos males é o menor deve ter como referência um ideal substancialmente distinto de qualquer um dos objetos da comparação, e mesmo que esse ideal não pareça atingível a curto ou médio prazo? A resposta para essas questões pode ser afirmativa, mas, se for, não se trata de algo cuja evidência salta aos olhos e, portanto, requer argumento.

Os dois problemas recém-examinados confirmam a opinião de que uma teoria de estado final não é suficiente para a realização de comparações. No mínimo, é preciso adicionar a essa teoria um critério de proximidade com precisão suficiente para embasar comparações, bem como um argumento em defesa desse critério, como quer que seja precisado. Nenhum desses requisitos é atendido por uma teoria de estado final como tal, já que, ao se ocupar exclusivamente com a descrição de um estado de coisas perfeitamente justo, tal teoria se vê liberada da questão acerca de como mensurar a proximidade de mundos imperfeitos em relação a si ou da defesa do critério da proximidade como base para comparações.

Passemos agora à afirmação de Sen acerca da desnecessidade de uma teoria de estado final para a comparação de estados de coisas não ideais. Em relação a esse ponto, o argumento de Sen (2006, p. 222) é um tanto simples: se considerarmos que o que uma teoria de estado final descreve é o melhor em termos de justiça, dizer que uma teoria como essa

final como a de Rawls, que atribui prioridade às liberdades básicas em relação à equitativa igualdade de oportunidades (RAWLS, 1999a, p. 38). As razões para essa prioridade podem ser tais que a tornem válida apenas para as circunstâncias de uma sociedade perfeitamente justa, impedindo de afirmar que o fato de uma sociedade estar mais avançada do que outra quanto à garantia das liberdades básicas baste, por si só, para considerá-la mais próxima do ideal.

Para uma indagação similar, ver Simmons (2010, p. 22). 
é necessária para a realização de comparações é tão verdadeiro quanto dizer que precisamos saber qual é o monte mais alto do mundo para determinar qual de outros dois montes é o mais alto. Naturalmente, não precisamos; não precisamos saber o que é o "melhor" em algo para comparar diferentes portadores do valor em questão. ${ }^{11}$

Examino a seguir algumas críticas feitas a Sen em relação a esse último ponto. ${ }^{12}$ Pretendo demonstrar que as críticas falham, e que, portanto, Sen está certo também quanto à desnecessidade (e não apenas quanto à insuficiência) de uma teoria de estado final para comparações que permitam avaliar tentativas de melhora parcial. Antes, no entanto, é conveniente prevenir um mal-entendido a respeito do que Sen quer dizer. A afirmação segundo a qual uma teoria de estado final não é necessária para a comparação de estados imperfeitos pode ser confundida com a de que diferentes teorias de estado final dão lugar, em certas circunstâncias, a juízos de comparação idênticos. Deixando de lado o problema de uma teoria de estado final não ser suficiente para a realização de comparações, isso é verdadeiro, mas banal. Não precisamos, por exemplo, eleger uma entre diferentes teorias liberal-igualitárias, ou entre o liberalismo igualitário e o utilitarismo, para afirmar que um estado de coisas no qual um grande número de pessoas passa fome é inferior, em termos de justiça, a outro no qual isso não ocorre. Essa comparação pode ser feita sem a necessidade de uma teoria de estado final em particular, uma vez que, para chegar ao veredito comparativo, não é preciso eleger uma entre diferentes teorias desse gênero. A tese de Sen, contudo, não se confunde com essa constatação. O que ele diz não é que podemos resolver problemas comparativos de justiça sem ter de decidir entre teorias de estado final rivais, mas que comparações são realizáveis sem a necessidade de qualquer uma dessas teorias. ${ }^{13}$

Sen (2006, p. 223) também refuta uma outra assertiva acerca da relação entre comparações e teorias de estado final, segundo a qual as primeiras só são possíveis se permitem identificar o melhor exemplar possível daquilo que é comparado. Em tal hipótese, mesmo que uma teoria de estado final não tenha um papel epistêmico, postular a possibilidade das comparações pressuporia postular a possibilidade de uma tal teoria. A afirmação, contudo, é patentemente falsa, porque presume, injustificadamente, que comparações só são possíveis quando há um critério de ordenação completa, isto é, que torne comparáveis todos os pares de itens possíveis.

12 Note que a afirmação de Sen é quanto à desnecessidade de uma teoria de estado final para a comparação de estados de coisas imperfeitos. Isso é complemente diferente de definir teoria ideal como teoria de estado final e teoria não ideal como teoria sobre como o estado final deve ou pode ser alcançado (RAWLS, 1999b, p. 89). Entendida dessa maneira (isto é, como teoria transicional), é evidente que não pode haver teoria não ideal que não tenha uma teoria ideal como ponto de partida.

13 Boot (2012, p. 12) está certo, pois, ao dizer que o fato de certos juízos comparativos poderem se basear em diferentes teorias de estado final não implica que nenhuma teoria como essa seja necessária para a comparação. Essa ilação é, de fato, falsa, mas não me parece correto acusar Sen de realizá-la. 
Uma crítica à tese da desnecessidade é a que se refere ao fato de as comparações terem de se basear em uma consideração ou "valor de cobertura" (covering value) (BOOT, 2012). Não posso simplesmente comparar João e Maria. Para compará-los, preciso de um valor ou critério em relação ao qual compará-los (por exemplo, honestidade, estatura, sensibilidade musical etc.). Do mesmo modo, para comparar a justiça de dois estados de coisas, necessito de um valor ou critério à base do qual a comparação se realize, valor esse que é, no caso, obviamente o próprio valor da justiça. "Justiça”, no entanto, é uma base de comparação que pode ser constituída por um ou mais de um princípio e, no caso de uma pluralidade de princípios, uma descrição acurada do valor de cobertura envolve não apenas os princípios em si, mas também as relações entre eles. Por isso é que, segundo Boot (2012, p. 12), uma teoria de estado final é necessária para comparações em termos de justiça. É uma teoria como essa que daria conteúdo ao valor de cobertura dessas comparações, determinando qual ou quais são os princípios da justiça e como eles são ordenados.

Boot está certo quanto à necessidade de um valor de cobertura e, no que se refere às comparações que envolvem a justiça, também em dizer que esse valor é provavelmente complexo, isto é, constituído por uma pluralidade de princípios e pelas relações entre eles. Não segue daí, entretanto, que a comparação necessite de uma teoria de estado final. Nem toda teorização sobre os princípios da justiça e eventuais relações de prioridade corresponde a uma teoria desse gênero, porque não tem forçosamente em vista um estado de coisas perfeitamente justo. Além disso, contrariamente ao que Boot (2012, p. 10) presume, os critérios de justiça válidos para condições ideais não são necessariamente os mesmos válidos sob outras condições. As circunstâncias fáticas de sociedades imperfeitas e até mesmo a não mais do que parcial (se tanto) conformidade podem alterar o conteúdo ou as relações de peso entre os princípios de justiça. ${ }^{14} \mathrm{~A}$ garantia de liberdades básicas, por exemplo, pode ser prioritária em relação à maximização da riqueza dos cidadãos nas circunstâncias de uma sociedade perfeitamente justa, mas não em outras circunstâncias. ${ }^{15}$ Em suma, é correto afirmar que comparações pressuponham teorização sobre a justiça no sentido de uma

Não parece absurdo cogitar que A e B sejam os únicos princípios de justiça válidos para uma sociedade $\mathrm{X}$ justamente em razão do fato de não serem plenamente satisfeitos pela sociedade em questão, e que, com o aumento do grau de satisfação de A e B, a mesma sociedade passe então a se sujeitar aos princípios A, B e C.

Isso é, de fato, o que Rawls defende se entendermos que a teoria de estado final rawlsiana corresponde ao que ele designa como "concepção especial de justiça". Em condições de acentuada escassez, a prioridade das liberdades deixa de ser defendida e é suplantada pela "concepção geral de justiça”, um critério geral de distribuição maximin (RAWLS, 1999a, p. 54). Admitindo-se que o ideal de sociedade perfeitamente justa de Rawls inclua entre suas presunções fáticas uma escassez apenas moderada, a concepção geral de justiça pode ser então entendida como a solução teórica de Rawls para o problema da justiça em certas sociedades imperfeitas. 
definição da base sobre a qual essas comparações terão lugar, mas não que toda teorização assim implique uma teoria de estado final.

Outra crítica diz respeito ao perigo de comparações que ignorem um estado de coisas ideal (STEMPLOWSKA, 2008, p. 332; ROBEYNS, 2012, p. 160). Imagine que devamos escolher entre dois estados de coisas não ideais, A e B, e que o façamos com base em princípios de justiça válidos para sociedades imperfeitas. Se a comparação entre A e B for feita à base desses princípios, deixando de lado o ideal de uma sociedade perfeitamente justa e os princípios que a caracterizam, há o risco de que a comparação em questão favoreça uma opção que, embora superior de acordo com os princípios considerados, é menos propensa (em razão da dependência da trajetória) do que a opção preterida a levar ao estado ideal. Para não correr o risco de preferir $\mathrm{B}$, uma opção superior segundo os princípios válidos para condições de injustiça, em detrimento de A, uma opção que, embora inferior a B segundo esses mesmos princípios, é mais propícia à realização do ideal de uma sociedade perfeitamente justa, é recomendável não perder de vista esse ideal na comparação de estados de coisas imperfeitos como A e B.

Há uma diferença, entretanto, entre afirmar que uma teoria de estado final é condição necessária para a comparação entre as sociedades imperfeitas A e B e afirmar que essa comparação, uma vez realizada sem ter como base uma teoria de estado final, será uma fonte duvidosa de aconselhamento para reformas sociais. A crítica sob análise corresponde à segunda afirmação, não à primeira. Porém, como diz Swift (2008, p. 374), "as questões de comparar e guiar a ação são distintas" ("the 'comparative grading' point is distinct from the 'action guiding' point”). Para que A e B sejam comparáveis sob o valor de cobertura da justiça, basta que haja um ou mais princípios de justiça de acordo com os quais seja o caso de dizer que A é melhor do que B; B é melhor do que A; ou ambos são exatamente iguais. Esses podem ser os princípios de justiça válidos para estados de coisas imperfeitos, os quais, tal como se argumentou acima, não são necessariamente os mesmos princípios válidos para circunstâncias ideais. Robeyns tem razão em dizer, todavia, que, no que concerne à questão sobre o que deve ser feito (isto é, sobre as medidas a tomar para a reforma das instituições), uma comparação entre as opções A e B feita estritamente à base dos princípios de justiça válidos para estados de coisas imperfeitos pode ser desorientadora, já que corre o risco de deixar uma sociedade mais distante, em vez de mais próxima, do estado de coisas ideal. Isso não é muito diferente de afirmar que podemos querer ter um pouco menos de justiça agora para ter um pouco mais a longo prazo. Essa crítica ressalta, pois, a importância de um ideal mais ambicioso de justiça para a ação, mas é insuficiente no que respeita a negar a possibilidade de realizar comparações em termos de "justiça imperfeita".

Vale observar ainda que, no que se refere não mais à comparação, mas à ação, isto é, ao que se deve fazer, o trade-off entre justiça de curto e longo prazo pode ser apenas um entre muitos. É provável que também se tenha de abrir mão de fazer o que a justiça requer em 
nome de valores como a paz ou os direitos humanos. O mero fato, porém, de que, em nome da paz, acabe-se concluindo que é A e não B que deve ser feito não é em absoluto incompatível com afirmar que A e B são comparáveis em termos de justiça e que, em termos de justiça, B é melhor do que A.

É de indagar, por fim, o quanto considerações de justiça perfeita são, de fato, propensas a determinar a ação e, ao fazê-lo, contrariar recomendações baseadas em comparações feitas segundo os princípios de justiça válidos para estados de coisas imperfeitos. Com que frequência será de dizer que, embora B seja mais justo do que A, de acordo com os princípios válidos para as presentes circunstâncias, deve-se fazer A em nome da realização da perfeita justiça? Contra uma afirmação como essa há não apenas a indesejabilidade de seguir um caminho menos justo agora, como também o caráter probabilístico da afirmação segundo a qual abrir mão da justiça a curto prazo levará a um estado de coisas perfeitamente justo logo adiante. Nas circunstâncias de sociedades imperfeitas, pode ser difícil afirmar com muita margem de segurança qual de duas medidas é a mais propensa a conduzir a uma situação de perfeita justiça no futuro. É possível, pois, que, além de não ser necessária às comparações em termos de justiça, uma teoria de estado final tenha pouco peso nas deliberações sobre o que fazer em circunstâncias imperfeitas, em razão da incerteza sobre os efeitos mais remotos das medidas cogitadas.

\section{TeOrias de estado finAl E InJUStiçA (ATUAL) DO DiReito PRivado}

Na seção anterior, defendi as afirmações de Sen $(2006$; 2009) acerca da insuficiência e desnecessidade de uma teoria ideal (no sentido de teoria de estado final) para comparações entre estados de coisas imperfeitos. Significa isso que devemos renunciar as teorias da justiça de estado final quando se tratar de avaliar propostas de reforma de uma certa área da legislação, como o direito privado? A resposta é não. Nesta seção, procuro explicar por que, embora nem suficiente nem necessária para comparações, uma teoria ideal pode ser útil para a avaliação de propostas de reforma.

Uma primeira razão pela qual alguém interessado em avaliar propostas de reforma da legislação não deve desprezar teorias da justiça de estado final é que essas teorias permitem dizer se (e, se não, por que) a sociedade em questão é perfeitamente justa. São condições suficientes para rejeitar tentativas de reforma que apelam para a justiça de que o status quo seja perfeitamente justo e a reforma defendida, caso levada a cabo, ponha em risco a preservação desse estado de coisas.

Segundo, uma teoria de estado final também é útil para comparações à medida que os princípios de justiça válidos para um estado de coisas perfeitamente justo também sejam válidos para as condições não ideais sob as quais as comparações têm lugar, ou se os princípios válidos para essas comparações podem ser ao menos em parte deduzidos dos princípios válidos para a situação ideal. Se, de um lado, os princípios de justiça válidos para sociedades 
imperfeitas não são necessariamente os mesmos de sociedades perfeitas, tampouco há, por outro lado, razão para descartar de antemão a hipótese de que esses princípios no todo ou em parte coincidam ou, ao menos, estejam relacionados o suficiente para que a reflexão acerca de uns seja epistemicamente útil em relação aos outros. Uma estratégia seria tomarmos como ponto de partida os princípios característicos de sociedades perfeitamente justas para então tentar determinar se, e com que modificações necessárias, esses princípios seguem tendo validade em condições de injustiça. Em outro possível cenário, o sentido da investigação se inverte, isto é, parte-se dos princípios válidos para condições não ideais para então indagar quais deles permaneceriam válidos em condições ideais. Não há, à primeira vista, razão de ordem metodológica para rejeitar seja o movimento "de cima para baixo" (isto é, do ideal para o não ideal), seja o contrário, embora a predileção por teorias de estado final na filosofia contemporânea facilite seguir a primeira opção. ${ }^{16} \mathrm{O}$ importante, em todo o caso, é que o fato de teorias de estado final não serem nem necessárias nem suficientes para a comparação de estados de coisas imperfeitos não é, por si só, razão para que essas teorias sejam consideradas irrelevantes para o julgamento de propostas de reforma em circunstâncias não ideais. ${ }^{17}$

Admitindo-se que uma teoria de estado final seja útil para avaliar propostas de reforma da legislação porque pode ajudar a determinar os princípios de justiça válidos para a comparação entre sociedades imperfeitas, a teoria em questão é uma teoria restrita à área da legislação em questão ou (no caso em que o objeto da justiça seja mais amplo) ou é uma teoria total da sociedade justa? Se há uma relação entre os princípios de justiça válidos para sociedades ideais e não ideais (de tal maneira que se possa partir de uns para chegar aos outros), então quem quer que se disponha a determinar os princípios a aplicar sob condições de injustiça com base na descrição de uma sociedade perfeitamente justa deve se preocupar em ter como referência a descrição mais acurada possível de uma sociedade assim. Em consequência, entre um ideal de justiça total e ideais de justiça parcial, é o primeiro que deve ser preferido, tendo em vista a possibilidade de que a justiça para uma determinada área varie em função do que se verifica nas demais. À medida, pois, que se queira recorrer a uma teoria de estado final para chegar aos princípios que devem servir de base

16 Um exemplo proeminente da estratégia “de cima para baixo” é Dworkin (2000, p. 162-180), que primeiro descreve uma situação ideal de distribuição de recursos para, a seguir, propor uma teoria da melhora para sociedades imperfeitas.

17 O texto acima argumenta acerca da importância de teoria de estado final para comparações que sirvam como base para a avaliação de mudanças em sociedades imperfeitas. Isso, porém, não é tudo. Como afirma Robeyns (2012, p. 160), além de guiar a ação, uma teoria de estado final pode atender ao interesse estritamente cognitivo de determinar se e o quanto as sociedades em que vivemos discrepam de uma sociedade perfeitamente justa. 
para avaliar propostas de alteração de uma área do direito, é preferível ter como referência uma teoria total, isto é, compreensiva de todo o objeto da justiça, e não restrita à área em questão.

\section{Conclusão}

Neste artigo, tratei da importância do contraste entre teoria ideal teoria não ideal de justiça para a avaliação de propostas de alteração pontual da legislação. Dispensei especial atenção a uma das várias acepções da distinção, segundo a qual, enquanto uma teoria ideal corresponde a uma teoria de estado final, uma teoria não ideal é limitada à comparação de estados de coisas imperfeitos.

Defendi a afirmação de Sen $(2006 ; 2009)$ de que uma teoria de estado final não é nem suficiente nem necessária para a comparação entre estados de coisas não perfeitamente justos. Em relação à segunda parte da afirmação, a mais controvertida, argumentei que, embora a comparação de estados de coisas imperfeitos com base na justiça requeira, inegavelmente, uma teorização sobre princípios da justiça, esses princípios não são necessariamente os mesmos válidos para circunstâncias ideais de plena realização da justiça. O fato, além disso, de que reformas que não tenham em vista uma teoria de estado final corram o risco de afastar uma sociedade do ideal da perfeita justiça não contradiz a afirmação de que é possível comparar estados de coisas apenas com base nos princípios de justiça válidos para sociedades atuais imperfeitas. Ao decidir sobre o que fazer, pode ser preciso eventualmente escolher entre mais justiça agora e mais justiça depois, isto é, entre o estado de coisas mais justo de acordo com os princípios válidos para as circunstâncias atuais e o mais propenso a conduzir a uma situação de perfeita justiça no futuro.

Nada disso, entretanto, faz com que uma teoria de estado final seja irrelevante de um modo geral e, no que respeita à indagação inicial do trabalho, irrelevante para avaliar propostas de reforma pontual. Uma primeira razão pela qual uma teoria ideal (entendida como teoria de estado final) não deve ser desprezada é que ela pode levar à conclusão de que certas sociedades já são perfeitamente justas, autorizando, assim, o rechaço a tentativas de modificação do status quo. É possível, também, que haja uma suficiente afinidade entre os princípios de justiça de sociedades ideais e não ideais para que a discussão sobre os primeiros seja útil para a descoberta dos segundos. No entanto, à medida que uma teoria de estado final constitua um ponto de partida promissor para a definição dos princípios de justiça com base nos quais propostas de reforma devem ser avaliadas, é preferível que a teoria em questão seja uma teoria total, isto é, compreensiva de todo o objeto da justiça, em vez de restrita a uma certa área do direito. 


\section{NOTA DE AGRADECIMENTO}

$O$ autor agradece a um(a) parecerista anônimo(a) pelos comentários e sugestões valiosas, inclusive quanto ao escopo do artigo, bem como à Revista Direito GV pelo eficiente trabalho de revisão e edição.

\section{REFERÊNCIAS BIBLIOGRÁFICAS}

BOOT, M. The Aim of a Theory of Justice. Ethical Theory and Moral Practice, 15, 2012, p. 7-21.

DWORKIN, R. Sovereign Virtue: The Theory and Practice of Equality. Cambridge: Harvard University Press, 2000.

KORDANA, K.; TABACHNICK, D. H. On Belling the Cat: Rawls and Tort as Corrective Justice. Virginia Law Review, 92(7), 2006, p. 1.279-1.310.

HAMLIN, A.; STEMPLOWSKA, Z. Theory, Ideal Theory and the Theory of Ideals. Political Studies Review, 10, 2012, p. 48-62.

RAWLS, J. A Theory of Justice (ed. rev.). Cambridge: Belknap Press, 1999a. The Law of Peoples. Cambridge: Harvard University Press, $1999 \mathrm{~b}$.

RIPSTEIN, A. The Division of Responsibility and the Law of Tort. Fordham Law Review, 72(5), 2004, p. $1.811-1.844$.

ROBEYNS, I. Ideal Theory in Theory and Practice. Social Theory and Practice, 34(3), 2008, p. 341-362. Are Transcendental Theories of Justice Redundant? Journal of Economic Methodology, 19(2), 2012, p. 159-163.

SIMMONS, A. J. Ideal and Non-ideal Theory. Philosophy \& Public Affairs, 38(1), 2010, p. 5-36.

SEN, A. What Do We Want from a Theory of Justice? Journal of Philosophy, 103(5), 2006, p. 215-238. The Idea of Justice. Cambridge: Belknap Press, 2009. 
STEMPLOWSKA, Z. What's Ideal About Ideal Theory? Social Theory and Practice, 34(3), 2008, p. 319-340.

SWIFT, A. The Value of Philosophy in Non-ideal Circumstances. Social Theory and Practice, 34(3), 2008, p. 363-387.

VAlEntini, L. Ideal Vs. Non-ideal Theory: A Conceptual Map. Philosophy Compass, 7(9), 2012, p. 654-664.

Leandro Martins Zanitelli

Professor Adjunto da Faculdade de Direito e Ciências do Estado da Universidade Federal de Minas Gerais.

leandrozanitellidagmail.com 